\title{
Knowledge and Error in Early Chinese Thought
}

\author{
Chris Fraser \\ University of Hong Kong
}

We are all familiar with perceptual illusion. Walking home at twilight, we see a person resting on a park bench ahead, only to discover a few steps later that the "person" is actually a small tree by the bench. Washing our hair in the shower, we hear the phone ring, only to check the phone log afterwards and find no missed calls. Such everyday experiences inspire the traditional skeptical argument from illusion. Illusions confirm that our senses sometimes deceive us, a simple form of the argument runs. Hence sense perception is too unreliable to yield knowledge. For perhaps it always deceives us, or at least we cannot be sure when it does and when not.

The argument from illusion, in its various guises, presents a perennial challenge for epistemologists. ${ }^{1}$ Versions of the argument have had a central role in motivating skepticism in both its ancient and modern forms. The argument drives the foundationalist search for absolutely certain starting-points for belief, and it contributes to the transcendental anxiety that epistemological coherentism or holism might allow our system of beliefs to lose touch with independent reality, such that empirical thought degenerates into mere "frictionless spinning in a void" (McDowell 1996: 11).

An intriguing aspect of early Chinese epistemology is that the argument from illusion plays no comparable role, even though perceptual illusion is explicitly considered in two of the most important pre-Hàn epistemological texts, the Mohist “Dialectics” 《墨辯》 and Book 21 of the Xúnž 《荷子》, “Resolving Obscuration 解敉.”2 Neither the Mohists nor Xúnzľ regards illusion as grounds for skepticism or a threat to knowledge. To the contrary, an implicit theme of Xúnž̌'s discussion is that familiar cases of illusion show that perceptual knowledge is reliable, not unreliable, since agents who employ their cognitive abilities 
properly will not be misled in such situations.

The aim of this paper is to sketch how knowledge and error are understood in early Chinese thought and by so doing to explain why illusion raises no deep skeptical worries for early Chinese thinkers, none of whom even considers a skeptical argument from illusion. The explanation I propose turns on two main claims. The first - which I will merely sketch, without defending in detail - is that the power of the argument from illusion rests on what I will call a "representational" conception of mind and knowledge. On such a conception, perceptual illusion occurs when the senses misrepresent the state of the world. Such misrepresentation raises the possibility of a lasting or comprehensive gap between how things seem to the agent and how they really are. This possibility generates the skeptical force of the argument from illusion.

The second claim is that early Chinese thinkers understand mind and knowledge mainly in terms of competence or ability, not representation. ${ }^{3}$ For them, the major function of the $x \bar{i} n$ 心, or "heart," is to guide action by discriminating different kinds (lè $i$ 類) of things, thus triggering skilled responses to them. ${ }^{4}$ Knowledge is understood primarily as a reliable ability to discriminate things and respond to them appropriately — minimally, by predicating appropriate general terms of them. To know is thus to be able to perform certain tasks competently. Cognitive error is a form of incompetence or ineptitude in discriminating and responding to things. Since incompetent, inept performances nevertheless do not cease to be performances - they genuinely engage with the world, albeit inappropriately — error is not associated with the possibility of the agent somehow failing to connect with mindindependent reality. Hence error due to illusion raises no skeptical worries. Conditions in which illusions occur make correct discrimination more difficult, but a competent agent knows how to cope with them. Should an agent be misled by an illusion, the explanation is not that she has mistaken appearance for reality, but that she has responded to only some 
features of her circumstances, overlooking other relevant features. She has attended to part of her situation at the expense of a correct response to the whole. For early Chinese epistemologists, I propose, the distinction between part and whole takes the place of that between appearance and reality in explaining perceptual error and cognitive error more generally. ${ }^{5}$

In what follows, I first briefly explain what I mean by a representational conception of mind and knowledge and how it motivates the argument from illusion. I then review the conception of knowledge in the earliest Chinese texts that explicitly address epistemological issues - the core chapters of the Mòž 《墨子》—showing how knowledge is linked to ability or competence. Next, I explain how the later Mohist "Dialectics" develops this conception of knowledge, particularly with respect to perception, identifies potential causes of error, including illusion, and provides the resources for an intriguing, non-representational explanation of error, including perceptual error. I then turn to the second major early Chinese treatment of epistemological issues, Books 21 and 22 of the Xúnzǐ. I first summarize Xúnž̌’s theory of knowledge, including perceptual knowledge, and then examine his account of cognitive error, including perceptual error and illusion. Finally, I sketch the form that skepticism takes in the early Chinese intellectual milieu. Throughout the discussion, I will highlight the respects in which the treatment of knowledge in different early Chinese texts tends to overlap and thus appears to reflect a largely shared underlying theoretical framework. I will survey the epistemological views in these texts in some detail, partly to clarify them for non-specialists and partly to illustrate the high degree of coherence between the textual details and the overarching interpretation proposed.

\section{Representation and Illusion}

The argument from illusion moves from the occurrence of perceptual error in isolated instances to the conclusion that perception might be wholly unreliable or that we are unable 
to tell in any particular case whether it is reliable or not. For the argument to have any force, it must presuppose a conception of mind and knowledge on which the possibility of frequent, widespread disparity, or even a comprehensive gap, between thought and the world is intelligible. I suggest that a general feature of conceptions of mind and knowledge that render such a disparity possible and intelligible is that they appeal to a type of indirect, representational structure to explain the relation between the epistemological subject and the world.

This suggestion is not a historical hypothesis. The claim is not that philosophers throughout history who have deployed versions of the argument from illusion or found them worrying each articulated or linked it to a conception of mind centered on an explicit notion of representation. Rather, the suggestion is an attempt to identify, in general, structural terms, an implicit feature of conceptions of mind or knowledge that explains how the everyday occurrence of illusion might motivate skepticism. The claim is that this structural feature is a conception of the mind as having direct access only to some intermediate entity that is in some sense "internal" to thought—such as ideas, impressions, phainomena, appearances, sense data, experiences, or a conceptual scheme-whose function is to represent or indicate how the "external," thought-independent world is. Knowledge then lies (partly) in holding, on the basis of such entities, cognitive attitudes that accurately represent or correspond to the world. For my purposes, the crucial feature of such a conception of mind and knowledge is that, because the intermediate entities are merely go-betweens, not features of the world itself, they inherently stop short of the world. There is thus a permanent possibility that the intermediaries have misrepresented how things are on the other side. ${ }^{6}$

On such a conception, cognitive error-false belief — is in effect a failure of accuracy or correspondence between the subject's representations of the world and how the world actually is. Illusion is a species of such error that occurs when a subject's perceptual 
experience is indistinguishable from a veridical case, yet the intermediate entities by which the subject accesses the world have misrepresented how things are. Since these entities are the subject's only means of intercourse with the thought-independent world, their unreliability in cases of illusion raises the skeptical question of how the subject could determine that they do not regularly or comprehensively misrepresent the world. For given that they stop short of the world, once we allow that they sometimes misrepresent things, the worry arises that a wholesale gap could open up between how they represent the world and how it in fact is, without the subject being able to discover this.

My suggestion, then, is that such skeptical worries are driven by a conception of the mind as engaging with the world only indirectly, via a sort of representational intermediary. ${ }^{7}$ Without such an indirect, representational conception of mind, illusion is unlikely to generate skeptical anxiety. Indeed, absent such a conception of mind, philosophers would probably be more likely to dwell instead on the fact that in everyday life, we normally discover and correct for illusions as soon as they occur. ${ }^{8}$

\section{The Early Mohist Conception of Knowledge}

The Mòz $\check{~ i s ~ t h e ~ e a r l i e s t ~ C h i n e s e ~ t e x t ~ t o ~ r e f l e c t ~ e x p l i c i t l y ~ o n ~ k n o w l e d g e ~ a n d ~ t h e ~}$ grounds by which we obtain it. The Mohists understand knowledge in practical terms, mainly as a skill, ability, or competence. To know something is to be able to do something correctly — most fundamentally, to be able to draw distinctions properly.

Mohist texts apply several interrelated conceptions of knowledge, or $z h \bar{\imath}$ 知. Probably the most common is a form of recognition, or "knowledge-of." ${ }^{9}$ Knowledge-of is manifested as the practical ability to correctly discriminate the referent of a word, or "name" (ming 名), that denotes the object of knowledge. To qualify as having knowledge of oxen, for instance, the agent must be able to reliably pick out the sorts of things denoted by the word "ox." The object of knowledge is typically regarded as a thing or event, denoted by a term, rather than a 
fact or proposition, expressed by a sentence. ${ }^{10}$ This is not to say that the Mohists have no functional analogue to factual or propositional knowledge, or "knowledge-that." The claim is rather that they conceptualize and explain such knowledge in terms of the ability to discriminate different kinds (lèi) of things. To know that $a$ is $F$ is to know to discriminate a as the kind of thing denoted by the term " $F$." Also, since to know a thing is to know how to discriminate it from other kinds of things, the object of knowledge is sometimes taken to be a distinction, as when the Mohists speak of "knowing the distinction between moral and immoral" (17/13). What we think of as evaluating an assertion or determining the facts or truth about something for the Mohists is a process of drawing distinctions, such as discriminating shi 是 (this, right) from $f e \bar{i}$ 非 (not, wrong), benefit (li 利) from harm (hài 害), yǒu 有 (presence) from wú 無 (absence), or tóng 同 (same) from yì 異 (different). For instance, in response to the fatalists' claim that wealth, longevity, and other matters are all fixed by fate, Mòzí is depicted as asserting that "we cannot fail to clearly discriminate (biàn 辨)" the controversial doctrine (35/5)—-that is, we must evaluate whether it is shì or fề and leads to benefit or harm.

The Mohist conception of knowledge as an ability or competence is illustrated in following passage, according to which knowledge lies not in making correct statements, but the ability to "select" the things denoted by a word, or "name." The object of knowledge is not a proposition, but concrete objects—white and black items.

Our master Mòzǐ said, "Now the blind say, 'What's bright is white, and what's dark is black.' Even the clear-sighted have no basis for changing this statement. But place white and black together and make the blind select among them, and they cannot know them. So as to my saying the blind do not know white and black, it's not on the basis of their naming, it's on the basis of their selecting." (47/23-24)

The passage depicts the blind as possessing factual or propositional knowledge about the colors white and black. Yet it claims that the blind do not qualify as "knowing white and black," because they are unable to discriminate white and black things in practice. The 
criterion of knowledge here is not understanding of a fact, nor the ability to state facts or use words correctly, but the ability to "distinguish the things" denoted by words (19/5). ${ }^{11}$

A further feature of the early Mohist conception of knowledge is that it includes no element corresponding to the justification condition in the traditional justified, true belief ("JTB") account of knowledge familiar from the Western tradition. One reason the Mohists assign no role to justification is probably that their conception of knowledge as correct discrimination and response implicitly incorporates reliability. The main role of justification in the JTB account is to disqualify accidentally true beliefs, such as lucky guesses, from counting as knowledge. The Mohists implicitly handle this issue by considering only correct discrimination that issues from a reliable ability to be knowledge. Knowledge is not merely a matter of discriminating things correctly in one case or another, but a competence or reliable capacity to discriminate them correctly in a diverse range of cases (17/11-12).

For the Mohists, then, knowledge is not a matter of having mental states with certain features, such as being justified or true, but an ability to perform certain skills. Accordingly, cognitive error is not explained as a failure of the agent's mental states to correspond to or represent the world accurately. It is understood as "disorder" (luàn 亂) or "confusion" (huò 惑) in discriminating things, in effect a failure to perform a skill correctly. For instance, the Mohists criticize those who fail to condemn unprovoked military aggression for the "disorder" in how they discriminate right from not-right (17/14).

How do we know we are discriminating such things correctly? To guide us in drawing and acting on distinctions properly, the Mohists introduce the concept of "models" or “standards" ( $f \breve{a}$ 法), paradigms or criteria of the things we seek to identify or norms of conduct we aim to follow. They conceive of such models largely by analogy to measuring tools, exemplars, or benchmarks. Typical examples are artisan's tools such as the carpenter's setsquare or the wheelwright's compass. Such models are applied to guide or check 
judgments or actions by evaluating whether the case at hand is relevantly similar to, and thus “coincides," with them.

The wheelwright and carpenter grasp their compass and setsquare and with them measure square and round in the world, saying, "What coincides is shi (this, right), what does not coincide is fêi (not-this, wrong)." (26/41-42)

Now the wheelwright takes his compass and uses it to measure the round and notround in the world, saying, "What coincides with my compass, call it 'round,' what doesn't coincide with my compass, call it 'not-round."' Thus round and not-round can both be known. (27/63-65)

The Mohists develop an explicit methodology for discriminating whether "statements" or "teachings" (yán 言) are shì or fềi by reference to three fundamental models: the historical precedent of the sage-kings; empirical evidence, specifically "the stuff of people's ears and eyes" (what people hear and see) ${ }^{12}$ and beneficial practical consequences $(35 / 7-10)$. The issue of how we know something is thus typically resolved by citing one or more models and examining whether some claim or thing is sufficiently similar to and thus "coincides" with them.

\section{Knowledge in the Mohist "Dialectics"}

As in earlier Mohist texts, epistemological passages in the later Mohist "Dialectics" focus not on the justification or truth of beliefs, or propositional attitudes, but on knowing how to distinguish what things are shì (this) or fềi (not) with respect to terms. The core expression of knowledge is again knowing how to apply terms to things correctly. However, the "Dialectics" identifies new aspects of knowledge to explain cases such as when an agent can correctly apply a term to a thing but not identify it perceptually or can recognize a thing under one name but not another. Here I will not present an exhaustive account of the epistemology of the "Dialectics," but only survey a handful of passages relevant to perceptual knowledge. $^{13}$

According to the later Mohists, humans who are alive and awake have a capacity or faculty called “the knowing" ( $z h \bar{l}$ 知), ${ }^{14}$ roughly akin to the capacity to have conscious states 
and perform cognitive functions. ${ }^{15}$ The functions of "the knowing" overlap with those other early texts ascribe to the heart (xin), a concept that plays no role in the "Dialectics." One function of "the knowing" is to know ( $z h \bar{l}$ 知) or recognize things in a manner the text describes as "contacting" them (A5), which probably refers to observation or perception. ${ }^{16}$ Characteristically, the Mohists explain this form of knowing by appeal to a practical ability: “To know is, by means of 'the knowing,' to pass by something and be able to characterize it." So knowledge is the ability (néng 能) to characterize (mào 貌) something encountered, probably by applying one or more terms to it. It is not understood as a mental state or propositional attitude that represents the world accurately. Functionally, an instance of correctly applying a term to something — such as by saying, "This is an ox" or by pointing at an ox and declaring, "Ox!" - can be interpreted as an expression of propositional knowledge. But the text explains such knowledge in terms of an ability, most likely to distinguish and name things. As in early Mohist epistemology, justification plays no part in this conception of knowledge.

Another passage (A80) gives a categorization of what appear to be different sources and different forms or objects of knowledge. ${ }^{17}$ Among the sources are personal observation ( qin 親), which is explained as “observing it there oneself." Along with the early Mohist notion of "the stuff of people's ears and eyes," this conception of "personal knowledge" (qin $z h i$ 親智, B70), or knowledge by observation, is the closest the Mohists come to articulating a notion of experience. Importantly, however, they themselves use no term actually interpretable as expressing a concept of experience. Nor do they posit epistemic or psychological intermediaries or representations between objects and the knowing agent, such as the ideas or impressions of Enlightenment conceptualism. ${ }^{18}$ Rather, perceived objects "enter" directly into "the knowing" (A98) by means of "the five routes," or the sense organs (B46). "Personal knowledge" contrasts with "knowledge by explanation" (shuō zhi 說智, 
B70), which is in effect knowledge obtained by inference or reasoning, and knowledge by “hearsay” (wén 聞), which refers to the reports or testimony of others (A80, A81).

Among the different forms of knowledge (A80), with their corresponding objects, are knowledge of names (ming 名, words), of stuff ( $s h i$ 實, including objects, events, and situations), and of the "matching" (hé 合) of names with stuff. Names are "that by which we call" (what we use to talk). Stuff is "what we call" (what we talk about). "Matching" is when name and stuff mate properly. The first two of these items concern what we might call "knowing-of." Knowledge of names probably refers to knowing words, without necessarily knowing how to correctly discriminate what shi (stuff, things) they refer to. An example would be the blind people discussed earlier, who can correctly use the words "black" and "white" to state that "Bright things are white and dark things are black" but cannot identify black or white objects. Presumably the criterion for knowing a name is knowing how to use it properly in at least some contexts. Knowing "stuff" probably refers to recognizing objects, events, or situations under some name - at the very least, under the "all-reaching" name “thing” (wù 物, A78), which applies to everything—but without necessarily knowing the correct name for them. Knowledge of "matching" would be knowing how to correctly discriminate the kind of stuff or thing to which some name refers. This is the practical knowhow that the blind lack in the earlier example. This ability to match names with things may correspond to the "characterizing" of things discussed above (A5). Knowledge of names, stuff, and "matching" may all fall under the more general conception of discursive knowledge presented in canon A6, according to which knowledge is "understanding" (ming 明), manifested as an ability to use “the knowing” to “sort things” (lùn wù 論物)— that is, to distinguish them into kinds corresponding to various names or phrases.

What determines whether a name and thing "match"? The Mohist explanation is again grounded in similarity to a model. A thing is "so" with respect to a predicate - that is, a name 
and thing "match"一when its features are "similar" (ruò 若) to those of a model ( $f \check{a}$ 法) of the kind of thing in question (A70-71). Models may include $y i$ 意, a thought or intention of the thing; measuring tools or other devices for identifying it; and exemplars of the thing. Canon A70, for instance, gives three examples of models, presumably for a circle or round object: a thought, a compass, and a circle. Features the Mohists cite as criteria of similarity include “shape and surface characteristics" (xíng mào 形貌) and “amount and number” (liàng shù 量數) (NO2). Things can “match” a model “exactly” (zhèng 正), as when a particular round figure is exactly the same shape as a model of a circle, or by whatever selected features are “appropriate" ( $y i$ 宜, A83), as when we deem people "swarthy" on the basis of the color of their skin, not their hair or eyes (A96). In some cases, discriminating different kinds can be difficult, because even if we have an exemplar of the kind to employ as a model, it may be hard to pin down just what features are "appropriate" or distinctive of that kind (B2).

To discriminate kinds properly, then, an agent must know how to select and apply a suitable model, how to pick out the features of particular individuals that are the "appropriate" or relevant basis for evaluating similarity to or difference from the model, and how to discriminate whether those features indeed resemble the model. ${ }^{19}$ The agent must then successfully exercise these abilities by attending to the appropriate features, correctly judging whether they meet the threshold for similarity to the model, and disregarding other, irrelevant features. In discriminating whether someone is swarthy, for instance, he must know to disregard black hair and pupils and attend only to skin color. In discriminating horses from oxen, he must know not to attend to their having molars and a tail, since both kinds of animals have these features (B66).

The "Dialectics" does not explicitly discuss the details of how agents make errors in discriminating different kinds of things. But given the above account of correct discrimination, we can make an informed conjecture as to how the later Mohists might 
explain perceptual error. The agent is likely to fail to discriminate correctly if he has not learned which features to attend to or how to gauge whether they count as similar to suitable models. He may also fail if he inadvertently neglects some relevant features, attends to irrelevant ones, or misjudges the degree of similarity to the model. Suppose the agent has indeed learned to discriminate individuals of the kind in question and can generally do so reliably, yet makes a mistake in a particular case. A likely cause is that the object he perceives is indeed similar to a relevant model, but only partly so. This partial similarity may lie in an inappropriate feature of the object, such as only its shape and not its surface features or, in the case of "swarthy," a person's hair instead of skin. Or it may lie in an appropriate feature, but be insufficient to qualify the object as an individual of the kind under consideration, as when the shape of an oval matches the shape of a model for "circle" partly but not entirely.

If this line of conjecture is correct, then we can understand why for the later Mohists perceptual error would not cast suspicion on the reliability of the senses, prompt the worry that appearances may fail to reflect reality, or raise the threat of losing touch with the world. Error occurs not when the world has somehow been misrepresented to the agent, but when the agent has discriminated on improper grounds - on the basis of partial but irrelevant or insufficient similarity between the object at hand and models of the kind under consideration. Not only does the agent remain in touch with the world, he has probably correctly noticed some similarity between the object and the kind. ${ }^{20}$ But he has overlooked other features pertinent to correct discrimination. In doing so, the agent has failed in the exercise of an ability at which he is normally competent. Thus understood, perceptual error results from faulty performance of a skill. It is comparable to a native speaker of a language absentmindedly saying something grammatically incorrect. The locus of error is not the nature of perception or thought, but the agent's inept performance: if the agent exercises his abilities 
properly, error will not occur.

Another passage in the "Dialectics" identifies several sources of doubt or confusion and thus potential causes of erroneous discrimination (B10). The first of these is accidental or atypical circumstances, which the Mohists see as the cause of perceptual illusion, among other errors. One example of such circumstances is a dense fog, which might cause an agent to mistake a man for an ox, an instance of illusion. Another is unseasonable weather, which might cause a person who has moved to a summer hut, expecting a heat wave, to instead feel cold. In this case, the error is due not to illusion, but to the fallibility of induction. The second source of doubt is insufficient evidence. We have reason to doubt that someone who lifts a load of feathers is strong, since feathers are too light for lifting them to be evidence of strength. The third source is causal overdetermination. A fighter's collapse might be because he drank alcohol before the match or because he was overcome by the noonday heat, and we may be unable to determine which factor was decisive. The fourth source is transience, when the object of discrimination is something that may cease. An example (the text does not give one) might be knowing the weather. When we fled indoors, we knew it was raining heavily, but the rain may have since stopped.

For our present purposes, the chief significance of this passage is that the fallibility of sense perception is not identified as grounds for confusion or error. Indeed, illusion or faulty perception is not even considered an independent category of error, but only one type of confusion due to unusual circumstances. The sources of confusion and potential error that concern the Mohists lie not in the nature of perception, nor the agent's relation to the world, but in contingent, well-understood features of the agent's circumstances - that things are unclear, atypical, causally overdetermined, transient, or provide inadequate evidence. With the possible exception of causal overdetermination, in each case confusion or doubt can usually be resolved by further investigation. 


\section{Xúnž̃ on Knowledge}

Xúnž follows the Mohists in tying knowledge to the ability to discriminate and name things. Like the later Mohists, he refers to the capacity or faculty of knowledge as "the knowing” ( $z h \bar{\imath}$ 知) (22/5). ${ }^{21}$ Knowledge is discriminating shì from fềi properly (2/12), such that the attitudes of "the knowing" "match" (hé 合) the distinctions between things (22/5). Distinctions underlie the use of names. The purpose of names is to discriminate different social ranks and similar from different things, so that intentions can be conveyed and tasks carried out (22/14-15). Names can be used this way because we are all creatures of the same kind, with the same sort of constitution (qing 情). Thus our sense organs detect things similarly, enabling us to establish conventions for the use of names to discriminate different kinds of things (22/16-17). ${ }^{22}$ Similarities and differences between features of things are “differentiated" ( $y i$ 異) by means of the sense organs - the eyes, ears, mouth, nose, and body (by which we differentiate pain, itching, temperature, texture, and weight). The heart (xīn) differentiates cognitive, affective, and conative features.

The heart also has a function called “the verifying knowing” (zhēng $z h \bar{\imath}$ 徵知), which is responsible for cognition (22/19). The "verifying knowing" is able to recognize sounds by means of the ears, shapes by means of the eyes, and so forth. The sense organs "record" (bì 簿) the features of things—-sounds, shapes, and so on—and the heart “verifies," or recognizes, them $(22 / 20)$. For an agent to qualify as having perceptual knowledge of something, her sense organs must "record" and become aware of it and the heart must “verify" it, such that the agent is able to "explain" (shuo 說) it (22/20-21). The text does not specify exactly what is meant by "explain" here. Probably the requirement is that the agent be able to correctly apply a name to the thing, and perhaps also to explain the grounds for discriminating the thing as belonging to the kind denoted by that name. If so, then this 
requirement is similar to that in the "Dialectics" that to have knowledge of something, an agent must be able to "characterize" it (A5) or "sort" it (A6). In both cases, knowing how to apply a word to a thing is a criterion of knowledge, which is inherently linguistic or conceptual. $^{23}$

A further similarity to the "Dialectics" is that Xúnzǐ's theory of perceptual knowledge assigns no role to anything comparable to the Cartesian-Empiricist notion of ideas or impressions, nor to any other form of epistemic or psychological intermediary. ${ }^{24}$ The text's theoretical framework comprises only features of things - such as shape, sound, sweetness, odor, or heat - the sense organs, which differentiate these features, and the heart, which employs the sense organs to "verify" or recognize them.

\section{Xúnzǐ on Cognitive Error}

An entire book of the Xúnžl_ "Resolving Obscuration"- is devoted to the topic of cognitive error. This text explicitly presents what I call the early Chinese "part-whole" conception of knowledge and error. The book's main theme is that errors in thought and action — errors in discriminating things and responding to them correctly—are due to what it calls “obscuration" or "blinkering ( $b i$ 蔽)," which can be avoided by employing the heart properly. Error occurs when agents become fixated on, and thus "obscured" or "blinkered" by, one "bend ( $q \bar{u}$ 曲)" or “corner (yú 隅)" of things, leaving them ignorant of the "overall pattern (dà $l \grave{l}$ 大理)" $(21 / 1,21 / 25)$. It is due not to subjective misrepresentation of the mindindependent world, nor to a gap between appearance and reality, but to fixing our attention in the wrong direction, such that we consider only some factors rather than all those relevant to discrimination. Erroneous discrimination is thus not wholly mistaken. The problem is that it is biased or one-sided and so only partly correct. ${ }^{25}$

According to Xúnž̌, such bias occurs because the heart is disturbed, misdirected, or hampered by internal conditions, such as emotions or obsessions, or external conditions, such 
as darkness, interference with the sense organs, or alcohol. These conditions impede the agent in responding to relevant aspects of the "overall pattern" in some situation.

Conscientious, competent agents can avoid error, because they know how to employ the heart so as to prevent such conditions from interfering with correct discrimination. Perceptual error thus is not ascribed to flaws in the functioning of the sense organs, nor is it considered evidence that perception is inherently deceptive or unreliable. It occurs not because perception or the senses are untrustworthy, but because agents have failed to employ their capacities properly. ${ }^{26}$

Xúnž̌ applies this theory to explain error on two levels, the general level of recognizing the overall dào 道 (way, teachings) or values one should live by and the concrete level of conducting oneself according to a particular dào. As examples of error on the general level, he criticizes other philosophers who emphasize some values but, according to Xúnž̌, are blinkered to others. The problem with rival thinkers such as Mòzǐ or Zhuāngž̌ 莊子, Xúnž̀ thinks, is not that their teachings are utterly wrong, but that they are partial, one-sided, or incomplete. Each possesses only "one corner of the dào" and is blind to the rest (21/2425). Such blinkering typically occurs when people are partial to what they have already learned and prefer not to hear of its flaws or the advantages of other approaches (21/3-4). It thus prevents them from seeking what is right $(21 / 4)$.

Almost anything can cause one-sidedness or blinkering, according to Xúnžr. His fundamental explanation of the cause of blinkering is that the various differences between things tend to obscure each other, thus disrupting our ability to "sort" or "grade" (lún 倫) things properly $(21 / 7,21 / 29)$. (Recall that the ability to sort things correctly is also a criterion of knowledge for the Mohist "Dialectics," according to the conception of "understanding" presented in canon A6.) The text does not elaborate, but Xúnžr's idea is probably that onesidedly or injudiciously attending to any one distinction or value makes us prone to overlook 
others that may also be pertinent. This failing is the crux of his attack on the one-sidedness of rival thinkers: he claims that they each emphasize one value or base their dào on one notion or technique at the expense of other equally important ones (21/21-26). Mòž́, for instance, was "blinkered by utility and did not know cultural form" (21/21): he focused so one-sidedly on material utility — and thus the benefit/harm distinction — that he neglected the importance of cultural or aesthetic form. In such cases, says Xúnž̌, our recognition of "that one"-one side of a distinction - interferes with our understanding of "this one"-whatever falls on the other side (21/38). A further dimension of the problem is that any distinguishing feature we attend to in discriminating things biases us toward understanding them specifically by reference to that feature, when other patterns of similarity and difference are always present as well. A trivial example is that in attending to what is desirable about something, we may overlook what is detestable about it, and in attending to what is beneficial about it, we may overlook what is harmful (3/45-49). On a deeper level, any values or norms we live by will tend to blinker us toward alternative values and ways of life. ${ }^{27}$

The second level of error Xúnzǐ considers is performance error in following a particular dào. Even if an agent is committed to following the right norms or dào, the agent may still commit errors in concrete situations. I will discuss this form of error in the section below on Xúnž̌’s treatment of illusion, where I will argue that his underlying explanation again lies in one-sidedness. Error occurs when the agent has attended to some features of the situation while overlooking other relevant features.

Xúnž̌'s part-whole conception of error and knowledge articulates ideas that were apparently widely shared among third-century B.C.E. Chinese intellectuals. Like Xúnž̆, several books of the Zhuāngž̌ criticize proponents of other views for their "partial" grasp of the dào. ${ }^{28}$ Two chapters of the The Annals of Lü Buwei 呂氏春秋 advance a part-whole explanation of error similar to Xúnž̌'s. ${ }^{29}$ Rather than using Xúnž̌’s term bì, the Annals 
ascribes error or misjudgment to being "biased" or "confined" (yò 直), typically by personal preferences. "When people are confined by something, indeed they will take daylight to be darkness, white to be black, and a sage-king like Yáo to be a tyrant like Jié. Being confined makes for serious mistakes." ${ }^{30}$ Like Xúnž̌, the text attributes such bias to how agents direct their attention: "One who looks toward the east does not see the west wall; one who gazes toward the south does not observe the north. The intention has something it is fixed on" (Knoblock and Riegel 2000: 286). Xúnžr's part-whole account also coheres well with the explanation of error I suggested can be derived from the Mohist "Dialectics." On my interpretation, for the Mohists, error occurs when the agent attends to the wrong features of things or overlooks relevant features. Xúnž would explain this by saying that the agent has been blinkered, either by incorrect training or by attending to some features at the expense of others.

\section{Avoiding Error}

This and the following subsection review in detail Xúnzǐ’s discussion of the causes of error and how to avoid or resolve them. The purpose of these sections is to illustrate how the details of Xúnž̌'s theory cohere with a competence model of knowledge and a part-whole model of error.

Xúnzì regards the use of the heart to discriminate things and guide action as a field of skill or technique, which he calls “arts of the heart (xīn shù 心術)" (21/28). As with any skill or art, performance in discrimination can be improved through training and conscientiousness. For Xúnž̌, as for many early Chinese thinkers (excepting the Mohists and the Zhuāngž̌, which parodies the idea), the heart is the "ruler (jūn 君)" of the other organs $(21 / 44,17 / 12) .{ }^{31}$ As we have seen, the heart is responsible for discriminating things on the basis of differences between them detected via the sense organs. Through its discriminating function, the heart handles cognition, judgment, and reasoning. But Xúnzǐ sees these as 
subsidiary operations; the heart's chief function is to guide action. ${ }^{32}$ In one place, Xúnzǐ describes the heart as the "labor supervisor (gōng zăi 工宰)" (22/40) of the dào—it is responsible for managing the other organs and the person as a whole so that the work of following the dào is performed properly. For the agent to discriminate and act according to the dào, the heart must be employed effectively. On their own, the sense organs can be obscured ( $b i)$ by external conditions, as when darkness obscures vision. But such obscuration need not lead to erroneous discrimination if the heart is employed competently. On the other hand, "if the heart is not employed at it," Xúnzǐ says, "though white and black are before us, the eyes do not see them; though thunder drums are beside us, the ear does not hear them" $(21 / 4-5)$

To discriminate properly, the heart must maintain a balanced, attentive equilibrium, like that of a soloist awaiting the conductor's cue or a basketball player compensating for an opponent's feints. A key to proper performance-in cognitive discrimination as in sports and performing arts — is to prevent things from disrupting this equilibrium by pulling the heart off balance, leading to blinkering and one-sided, erroneous execution.

Thus the human heart can be compared to a pan of water. Place it upright and do not move it, and the sediment settles to the bottom and the clear water rises to the top. Then it is sufficient to see your beard and eyebrows and discern the fine patterns on your face. A breeze passing over it, the sediment moves below and the clear water is disturbed on top, and you cannot get even the general outline right. The heart too is like this. So guide it with pattern, cultivate it with clarity, and let nothing bias it. Then it will be sufficient to fix shi-fêi and settle doubts. If minor things pull it about, then externally one's uprightness will be altered and internally the heart will be biased, and it will be insufficient to decide even gross patterns. (21/54-58)

As this passage indicates, Xúnzǐ holds that proper "guiding" and "cultivating" in the arts of the heart can train us to avoid error. To discriminate shi-fềi and resolve confusing circumstances reliably, we can train ourselves to maintain an impartial, upright stance and an undisturbed, unbiased heart.

The dào - in this case, Xúnzǐ’s preferred system of kinds (lèi 類), names (míng 名), 


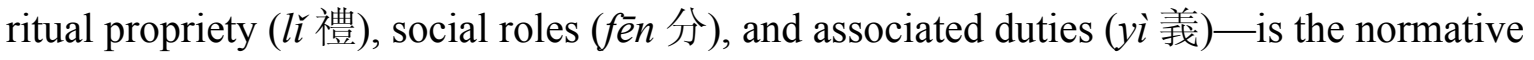
basis for such training. The dào provides an objective standard or "scale" (héng 衡, 21/2930) to guide discrimination and action. An expert in a particular field, such as farming, commerce, or a craft, approaches that field on its own narrow terms. But an expert in the dào approaches all things inclusively, in terms of their relation to everything else (21/51-52). Hence the gentlemen devotes himself wholly to mastering the dào and using it as a basis for examining things. Since he is focused fully on the dào, rather than particular interests or preferences, he is upright and unbiased; since he uses the dào as a basis for examining things, he is discerning in how he discriminates them into kinds. "Using impartial intentions to proceed with discerning sorting of kinds, one can manage the myriad things" (21/52-53).

Bias and error can thus be avoided by refraining from applying personal opinions or preferences and instead objectively weighing things according to the dào (21/28-30). To do this reliably, however, we must recognize the dào and train ourselves in it by being $x \bar{u}$ 虛 (“open,” “empty,” or “vacant”), $y \bar{l}$ 喜 (“focused” or “unified”), and jìng 靜 (“calm” or “still”) (21/34-35). By “openness,” Xúnžr means "not letting what one has already learned interfere with what is to be received" (21/36-37): though the heart is constantly storing things in memory, it can remain open to new learning. By "focused," he means "not letting that one interfere with this one" (21/38). As we have seen, the nature of cognition for Xúnžr lies in discriminating things from each other. In doing so, he says, we implicitly recognize both things jointly, in relation to each other, and thus the heart is directed in two ways. Still, he says, we can also understand each thing on its own, without interference from how we discriminate it from other things. By "calm," he means "not letting dreaming and fancies disrupt knowing" (21/39). The heart is always in motion, Xúnž̌ thinks: during sleep, it dreams; while unoccupied, it wanders in idle fancy; while engaged, it plans. Yet we can also maintain a form of calm, through which we can avoid distraction by the imagination or 
irrelevant thoughts. By being open, says Xúnzǐ, one who seeks the dào may enter it; by being focused, one who undertakes to follow it may master it; by being calm, one who contemplates the dào can become discerning (21/39-40). These psychological techniques, along with training in dào, supposedly provide a means of preventing blinkering or onesidedness and thus error.

\section{Xúnzǐ on Illusion}

"Resolving Obscuration" explicitly discusses perceptual error, including error due to illusion. The conception of "obscuration" or "blinkering" (bi) shifts slightly in this discussion. Here, instead of attributing obscuration or blinkering primarily to psychological factors that bias the agent's attention and discrimination, Xúnzǐ attributes it to external circumstances that interfere with normal perception, as when darkness hampers vision or distance obscures the size of things. His main claim is not that sense perception is misleading or unreliable, but that only a "fool" (21/73) injudiciously discriminates whether things are "so" or not in potentially confusing circumstances. A cognitively competent agent recognizes and compensates for such circumstances and so avoids error. Part of our basic cognitive competence, for Xúnž̆, is the ability to respond to "doubtful" conditions by withholding judgment accordingly:

Whenever in observing things there is doubt, if the heart within is not stable, then external things are unclear. Our thinking (lï 慮) being unclear, ${ }^{33}$ it is not yet permissible to fix “so" or "not-so." (21/67-68)

With appropriate care, error can be prevented even in confusing perceptual conditions. For ultimately it is due not to the conditions that temporarily obscure observation, but to how we employ the heart in response to them.

Xúnž̌ mentions seven types of circumstances in which in observation there are confusion and grounds for doubt (21/68-73). First, there are familiar cases of perceptual illusion and hallucination. Someone walking in the dark may take a horizontal stone to be a 
crouching tiger or an upright tree to be a person following him, because "the darkness obscures his eyesight." Pressing on our eyes, we take one thing to be two; covering our ears, we take a "mò mò" sound to be "xiōng xiōng,"34 because "the circumstances disrupt the sense organs." From a mountaintop, oxen below look similar to sheep, because "the distance obscures their size." From far below, tall trees on a mountain look similar to chopsticks, because "the height obscures their length." The point of these examples is not that perception is deceptive or that appearances may fail to represent reality accurately. It is that we need to employ the heart carefully. An agent whose heart is stable and thinking is clear attends to the overall circumstances, not just to partial, yet misleading similarities between aspects of the situation and familiar things. "So from a mountaintop looking down at oxen, they are similar to sheep, but someone seeking sheep does not go down to lead them away. . . From the foot of a mountain looking up at trees, ten-meter trees are similar to chopsticks, but someone seeking chopsticks does not go up to break them off" (21/71-72). Presumably, the norms and skills involved in discriminating things such as tigers, people, number, sounds, sheep, and chopsticks include provisions for discounting or compensating for the effects of unfavorable observational conditions. So an agent competent in these norms and skills performs properly even in such conditions.

The remainder of the examples confirm that Xúnzǐ’s theme is not that perception or observation is deceptive, but that potentially confusing circumstances call for special care and discretion. The further examples are intoxication, unreliable means, and incompetent testimony. A drunk will foolishly attempt to leap a wide ditch, taking it to be a mere gutter, or will stoop while exiting the city gate, taking it to be a low doorway, because "the alcohol disrupts his spirit" (21/70). Here the issue is not perception, but how circumstances that disrupt normal functioning, as intoxication does, can cause massive failures of judgment. We do not discriminate whether we look attractive by our reflection in moving water, because 
"the water's position is disturbed" (21/72). Nor do we discriminate whether there are stars in the sky by asking the blind, because their "functional proficiency is confused" $(21 / 73) .{ }^{35}$ As with drunkenness, these would amount to attempting to discriminate things, as Xúnzǐ puts it, "by using confusion to resolve confusion." In such cases, error is almost inevitable (21/74).

For Xúnzǐ, then, error due to illusion is a subset of a more general sort of error resulting from an inept attempt to discriminate so from not-so in confusing circumstances when the heart is unstable and thinking unclear. The source of error lies in the agent's incompetence or poor judgment, not the misleading nature of perception or appearance. When illusion occurs, the agent discriminates on the basis of some genuine similarity between his circumstances and models or exemplars of the kind in question, and thus is indisputably in touch with the world. In some respects, the outline of a horizontal stone may indeed resemble that of a tiger, or the shape of distant oxen in the valley below may indeed resemble that of nearby sheep. The problem is that these limited similarities are an insufficient basis for discriminating the stone as a tiger or the oxen as sheep. For the similarity is only partial, and there are other, dissimilar features to which a competent agent should also attend, even if "confusing" or "obscuring" circumstances make doing so more difficult than usual. ${ }^{36}$ If agents do attend to the overall circumstances, employing a "stable" heart and "clear" thinking, they will recognize that the similarity is insufficient and will avoid error. Illusion thus provides grounds for concluding that perception is reliable, not unreliable, provided the heart is employed properly.

\section{Skepticism and Dream Arguments}

Skeptical doctrines typically exist in symbiosis with a particular conception of knowledge, the skeptic questioning whether knowledge under that conception is attainable. As we would expect, then, the conception of knowledge as a form of ability or competence shapes the expression of skepticism in pre-Hàn thought. The very notion of an ability entails 
that its exercise is generally reliable, for otherwise we would not think of it as an ability. Moreover, what we take to be abilities must on the whole be fairly successful ways of interacting with the world, or we as a species would have perished long ago. If, with early Chinese epistemologists, we think of knowledge as a reliable ability to discriminate and respond to things, clearly we regularly succeed in discriminating and responding to things according to some fairly useful system of norms, for otherwise we would be unable to go about our daily lives. Given these points, in early Chinese thought there is little motivation for skepticism about whether sense perception presents the world accurately, whether we might know only appearances and not reality, whether our subjective ideas and beliefs correspond to the external world, or whether language accurately captures the nature of reality. ${ }^{37}$ All of these skeptical concerns ultimately arise from a representational theoretical framework that early Chinese thinkers do not share. Instead, in this intellectual context, skepticism takes the form of questioning whether our system of norms for discriminating and responding to things — in effect, our dào — is correct or appropriate, whether the claim that it is has any purchase, and whether language, $f \check{a}$ (models), and other explicit guidelines genuinely have the capacity to guide us in following the dào reliably. These are the sorts of skeptical issues raised in the Dàodéjīng 《道德經》 and Zhuāngzĭ. That the dào we follow is genuinely a way of engaging with the world is not a matter of doubt. The question is rather whether there might be a more appropriate way — a more effective, unbiased, or comprehensive dào.

The claim that sense skepticism is not a concern in early Chinese thought might seem open to obvious counterexamples, for a pair of dream arguments figure prominently in the most important pre-Hàn skeptical text, Book 2 of the Zhuāngž̌, the "Discourse on Evening Things Out 齊物論.” Under the influence of Descartes, contemporary readers may be inclined to assume that dream arguments inevitably concern the reliability of sense 
perception. In fact, however, the dream arguments in "Evening Things Out" concern change or transformation, not perception. ${ }^{38}$ Their main point is that how we apply action-guiding distinctions - examples include delight versus dislike, social ranks such as shepherd or noble, and what I am versus what I am not—depends partly on contingent, shifting circumstances. As circumstances change, we may come to draw these distinctions differently, for we may gain more information, change how we weight different factors, or change our values. Thus we have two sorts of grounds for questioning whether our way of drawing such distinctions is conclusive: epistemic limitations due to our circumstances and potential shifts in our attitudes as circumstances change.

The first of the dream arguments questions how we apply evaluative, action-guiding distinctions - specifically, the distinction between delight and dislike. The text challenges even the most obvious application of the distinction: we delight in life and dislike death and so seek to preserve life and avoid death (2/78-79). Perhaps the radical change in our circumstances that death brings would lead us to delight in death more than life, just as Lady Lì, who wept when married off to the King of Jìn, later came to delight in her pleasant life with him (2/79-80). The experience of waking from a dream is cited as a vivid example of how evaluative attitudes can change with circumstances. Feeling delighted during a pleasant dream is justified. But if we awake to find ourselves in less pleasant circumstances, our attitudes change accordingly. The point is not that perception may be illusory or our access to the world unreliable. It is that how we draw value distinctions is as contingent as the judgments we make in a dream. We may feel confident about our judgments and then have them shift radically with an abrupt change in our situation (2/81-83).

The second dream argument is the well-known story of Zhuāng Zhōu's butterfly dream (2/94-96). In the dream, Zhōu finds it obvious that he is a butterfly. On waking, he finds it equally obvious that he is Zhōu. Noticing how a change in circumstance- 
awakening — affected the obviousness of whether he was a butterfly or Zhōu, he wonders whether he has now finally discriminated his identity correctly, for circumstances could change yet again. Between Zhōu and the butterfly there is surely a distinction, the text affirms. But Zhōu lacks grounds to determine conclusively which side of the distinction he is on. This, the text says, illustrates how things change (wù huà 物化, 2/96). The point of the story is thus to question whether discriminations we make in one set of circumstances hold for all, given that things inevitably change. It is not to doubt whether perception reliably represents reality.

\section{Conclusion}

The skeptical force of the argument from illusion grows out of a conception of mind and knowledge that allows for the possibility of a comprehensive or persistent gap between reality and our perception of it. A core feature of such a conception, I have suggested, is a broadly representational understanding of mind and knowledge. By contrast, early Chinese theories of mind and knowledge explain cognitive functions in terms of abilities or competence, not representation. Such theories leave no conceptual room for the notion of a gap between the agent and the world. An agent who commits a cognitive error, including perceptual error, is in contact with the world, just as one who burns the soufflé or hooks a golf drive into the trees is. The problem lies in faulty performance, not the inherently deceptive nature of perception or the unknowable character of reality. The mistaken agent has simply failed to pay attention to the right things or respond to them in the right way. Even in the case of perceptual error due to illusion, the agent is not regarded as misled by appearances or sense impressions that misrepresent reality. Rather, the agent is seen as in touch with the world and usually right about something, namely that whatever feature prompted the erroneous discrimination is indeed similar, at least partially, to a paradigm of the kind of thing the agent took it to be. 
As the preceding sections have shown, early Chinese texts present three sorts of explanations of cognitive error, including perceptual error. The first is an explanation of just what error is: it is confusion or failure in discriminating and responding to things. The second is a series of explanations of various psychological and environmental factors that can cause error. For a competent agent, who normally knows what he perceives, perceptual error is due to occasional performance failure arising from psychological factors such as carelessness, distraction, obsession, or nervousness, sometimes in conjunction with environmental factors such as indistinct or confusing observational conditions. The third explanation is a more general, partly metaphorical interpretation of what happens when such factors interfere with correct discrimination: the agent responds to some features of the circumstances while overlooking other relevant features, in effect responding to an unrepresentative or insufficient part of the situation rather than competently coping with the whole. At this general, abstract level, instead of a distinction between appearance and reality, early Chinese theorists explain error by appeal to a distinction between part and whole. Although only Xúnzǐ elaborates such a general, part-whole explanation in much detail, I have tried to show that a part-whole view coheres well with Mohist epistemology and with other early discussions of error, such as those in The Annals of Lü Buwei.

For pre-Hàn thinkers, the situation as a whole always provides sufficient features for the competent, conscientious agent to avoid perceptual error. We are expected to notice whether our circumstances are "confusing" and compensate accordingly, either by employing care and discretion in discrimination or by temporarily withholding judgment. In the rare case when we cannot discriminate correctly, even after investigation, we can at least determine the nature of the "obscuration" that prevents us from doing so. If we perform competently, then, we will either discriminate correctly or at minimum avoid error. Moreover, in pre-Hàn thought, agents are conceived of as performers of a dào, a continuing path or course of 
conduct. Instances of perceptual discrimination are thus seen as parts of an ongoing course of activity, not discrete, isolated judgments that stand or fall on their own. Hence if we do err, we can expect to discover and correct the mistake in due course. The foolish shepherd who discriminates distant oxen as sheep and hikes down to lead them back to the flock will revise his discrimination soon enough.

The object of skeptical doubt in pre-Hàn thought is not whether we ever succeed in interacting with the world competently — and thus obtaining knowledge of it — but whether our norms for interacting with it are uniquely or absolutely correct. Perhaps other norms might be equally or more justified, for other people or creatures, if not us. That we can achieve competence is not in doubt. The question is whether our form of competence is the only or the most appropriate one. ${ }^{39}$

\section{References}

Cua, A. S. 1985. Ethical Argumentation: A Study in Hsun Tzu's Moral Epistemology. Honolulu: University of Hawaii Press.

Dretske, Fred. 1981. Knowledge and the Flow of Information. Cambridge, Ma. MIT Press. Fraser, Chris. 1999. Similarity and Standards: Language, Cognition, and Action in Chinese and Western Thought. Ph.D. dissertation, University of Hong Kong. . 2006. "Zhuangzi, Xunzi, and the Paradoxical Nature of Education.” Journal of

Chinese Philosophy 33.4: 529-42. . 2009a. "Mohist Canons.” In The Stanford Encyclopedia of Philosophy (Summer 2009

Edition), edited by Edward Zalta.

http://plato.stanford.edu/archives/sum2009/entries/mohist-canons/. . 2009b. "Skepticism and Value in the Zhuāngzǐ." International Philosophical

Quarterly 49.4: 439-57.

Geaney, Jane. 2002. On the Epistemology of the Senses in Early Chinese Thought. Honolulu: 
University of Hawaii Press.

Graham, A. C. 1989. Disputers of the Tao. La Salle: Open Court. 2003. Later Mohist Logic, Ethics and Science. Reprint. Hong Kong: Chinese

University Press.

Hansen, Chad. 1983. Language and Logic in Ancient China. Ann Arbor: University of Michigan Press. 1992. A Daoist Theory of Chinese Thought. New York: Oxford.

Harbsmeier, Christoph. 1993. "Conceptions of Knowledge in Ancient China." In

Epistemological Issues in Classical Chinese Philosophy, edited by Hans Lenk and Gregor Paul, 11-30. Albany: SUNY Press. . 1998. Science and Civilisation in China, Vol. 7, Part 1: Language and Logic.

Cambridge: Cambridge University Press.

Knoblock, John. 1994. Xunzi: A Translation and Study of the Complete Works, vol. 3.

Stanford: Stanford University Press.

Knoblock, John, and Jeffrey Riegel, tr. 2000. The Annals of Lü Buwei. Stanford: Stanford University Press.

Ľ̌, Díshēng 李條生. 1979. Collected Explications of Xúnž̌ 《荀子集釋》. Taipei: Xuéshēng.

McDowell, John. 1996. Mind and World. Cambridge, Ma.: Harvard University Press. . 1998. "Knowledge and the Internal." In McDowell, Meaning, Knowledge, and

Reality, 395-413. Cambridge, Ma.: Harvard University Press.

Millikan, Ruth Garrett. 1987. Language, Thought, and Other Biological Categories.

Cambridge, Ma.: MIT Press.

Mòž̌. 1986. A Concordance to Mòzǐ 《墨子引得》. Harvard-Yenching Institute Sinological Index Series, Supplement no. 21 (reprint). Shànghăi: Shànghăi Gǔjí. 
Munro, Donald. 1969. The Concept of Man in Early China. Stanford: Stanford University Press.

Robins, Dan. 2008. “Xunzi.” In The Stanford Encyclopedia of Philosophy (Fall 2008 Edition), edited by Edward Zalta. http://plato.stanford.edu/archives/fall2008/entries/xunzi/.

Roetz, Heiner. 1993. "Validity in Zhou Thought.” In Epistemological Issues in Classical Chinese Philosophy, edited by Hans Lenk and Gregor Paul, 69-112. Albany: SUNY Press.

Sivin, Nathan. 1995. "State, Cosmos, and Body in the Last Three Centuries B.C." Harvard Journal of Asiatic Studies 55.1: 5-37.

Watson, Burton, tr. 1963. Hsun Tzu: Basic Writings. New York: Columbia University Press. Xúnž̌. 1966. A Concordance to Xúnzǐ 《荀子引得》. Harvard-Yenching Institute Sinological Index Series, Supplement no. 22. Cambridge, Ma.: Harvard University Press. Zhuāngž̌. 1956. A Concordance to Zhuāngzǐ 《莊子引得》. Harvard-Yenching Institute Sinological Index Series, Supplement no. 20. Cambridge, Ma.: Harvard University Press.

\section{Notes}

${ }^{1}$ For convenience, I will refer to "the argument from illusion," in the singular, though in fact there are a variety of arguments from illusion.

${ }^{2}$ The Mohist "Dialectics" is a modern label for the numerous short texts collected together in books 40-45 of the Mòž̆, which focus on language, knowledge, argumentation, ontology, and ethics, among other topics. Throughout the paper, I will refer to these texts collectively as the "Dialectics." They probably date from between 320 and 250 B.C.E. "Resolving Obscuration" is likely from the first half of the third century B.C.E. 
${ }^{3}$ Here I am developing a line of interpretation introduced by Hansen (1983: 64-65). To clarify, the claim here is not that early Chinese theorists do not ascribe representational functions to thought and language or understand them as having representational content. It is that their theoretical approach to language, thought, and knowledge centers on practical ability or competence, which provides the basis for their explanation of representational content. On these points, see Fraser (2009a), especially sections 4.2 and 6.

${ }^{4}$ The $x \bar{i} n$ is conceived of as a physical organ in the center of the body that combines cognitive, conative, and affective functions. Because early Chinese texts do not distinguish between reason and passion or the mind and heart, the word " $x \bar{\imath} n$ " is sometimes translated as "heart-mind."

${ }^{5}$ Moreover, as Jane Geaney correctly notes, in early Chinese thought "there is no sign of the view that sense discriminations must be transcended in favor of a super-sensible form of knowing," such as knowledge of Platonic forms or the Parmenidean unity (2002: 13). The absence of such a view, typically associated with the metaphysical belief that the changing world of sense perception is in some sense unreal or does not reveal the ultimate or fundamental nature of reality, may be a further factor explaining early Chinese thinkers' lack of interest in arguments from illusion.

${ }^{6}$ McDowell (1998) offers a contemporary account of skeptical worries arising from the argument from illusion that converges with some of my suggestions. McDowell (1996) links skeptical worries about empirical thought collapsing into "frictionless spinning in a void" to the idea that the exercise of conceptual capacities - as exercises of Kantian spontaneitymight be unconstrained by the world. This suggestion hooks up with my own insofar as a comprehensive gap between our scheme of representations and the world would be one cause of a lack of "constraint" or "friction." 
${ }^{7}$ Not all theories that explain mental states in terms of their representational content do so by means of such an indirect structure, of course. Approaches such as those of Dretske (1981) or Millikan (1987) assign no role to representational intermediaries and may converge in some respects with the ancient Chinese views I explore below.

${ }^{8}$ A second important factor behind some versions of the argument from illusion may be a simple fallacy in quantifier logic: inferring from the premise that the senses deceive us in some cases to the conclusion that they might deceive us in all. I suggest, however, that a representational conception of mind helps explain why this faulty inference might seem persuasive.

${ }^{9}$ Perhaps the most frequent use of the word $z h \bar{\imath}$ 知 (know) in early Chinese texts is in contexts in which it is best interpreted as "knowing-of" or "knowing-about," a sort of recognition, familiarity, or understanding. A second common use is to mean roughly "knowto" or "know-how-to," referring to a kind of competence or ability. Occasionally, zhī is used in contexts in which it is interpretable as "knowing that" and seems to refer to propositional knowledge. However, it is not clear that early Chinese thinkers themselves distinguish such contexts from "knowing-of." In any case, the Mohists' discussion of issues such as fatalism and the existence of ghosts indicates that the three sorts of knowledge are interrelated, and all three are explained by appeal to the ability to discriminate things properly: to know-that or know-of is to know-to discriminate different kinds of things correctly and apply the appropriate names or phrases to them. For opposing views, see Harbsmeier (1993), also reprinted in his (1998), and Roetz (1993).

${ }^{10}$ Grammatically, the classical Chinese verb $z h \bar{\imath}$ 知 (to know) usually takes either a noun phrase or a verb phrase as its object. Even when the object of knowledge is a fact or state of affairs, it is normally expressed as a noun phrase, rather than a clause. For instance, instead of 
"How do we know that promoting the worthy is the root of government?" the Mohists write the Chinese equivalent of "How do we know promoting the worthy's being the root of government?” (9/2). (References to Mòž̌ cite chapter and line numbers in Mòzǐ [1986].) Though I think it a mistake to read too much into contingent features of a thinker's language, this grammar might have encouraged the Mohists to think of facts as features of things, structured along the lines of phrases predicable of things, rather than as states of affairs, with a propositional structure.

${ }^{11}$ Against the Mohist position here, we might argue that this passage itself implicitly acknowledges that knowing how to use "names" is a discrete type of knowledge, distinct from knowing how to "select" things, and that the blind may possess the former even if they lack the latter. As we will see below, the later Mohist "Dialectics" incorporates this point into its account of knowledge.

${ }^{12}$ The "stuff of people's ears and eyes" has a double significance. On the hand, it refers to empirical observation, by contrast with the authority of tradition. On the other, it refers to what the common people can determine for themselves, by contrast with what they accept on the authority of the political elite. I thank Jane Geaney for reminding me of the importance of social class in interpreting this criterion.

${ }^{13}$ For a more detailed treatment, see Fraser (2009a). I should add the caveat that, as explained in Fraser (2009a), the textual problems with the Mohist "Dialectics" are so extensive and complex that any interpretation is partly conjectural. However, I think the key structural features emphasized here, such as the links between knowing, competence, discrimination, and language use, are among the aspects of later Mohist thought for which the textual evidence is quite strong. I should also point out that in calling a passage "relevant" to 
perceptual knowledge, I am not implying that it treats perceptual knowledge specifically and not other forms of knowledge as well.

${ }^{14}$ See canon and explanation A3 and A22. References to the "Dialectics" follow the numbering system in Graham (2003).

${ }^{15}$ The faculty or capacity of $z h \bar{\imath}$ here can also be interpreted as "the awareness," “consciousness," or "the intelligence" (the latter is Graham's translation [2003: 267]). I render it "the knowing" partly to highlight the partial analogy to the Lockean or Kantian notion of "the understanding" and partly to emphasize that its primary function is to know things. I translate Xúnž̌s concept of zhēng $z h \bar{l}$ 徵知 (“verifying knowing”) similarly below.

${ }^{16}$ I take canon A5 to refer to perceptual knowledge or, more precisely, knowledge originating in perception (which might include knowledge obtained from memory), because this seems the best explanation of the statement that knowledge is "contacting" (jie 接) things. The text itself does not explicitly specify that A5 refers to perception.

${ }^{17}$ Canon A80 lists seven items, of which the first three seem best explained as sources of knowledge: hearsay (wén 聞), explanation (shūo 說), and personal observation (qīn 親). The next four are names (ming 名), stuff (shi 實), matching (hé 合), and action (wéi 為). These seem best explained as either objects of knowledge or forms in which knowledge can be manifested — that is, by displaying the relevant competence in using names, discriminating stuff, matching names with stuff, or acting.

${ }^{18}$ As Geaney rightly observes, for early Chinese thinkers, "there is nothing to mediate and alienate the senses from the world" (2002: 13).

${ }^{19}$ Though their texts do not explicitly say so, I assume the Mohists would agree that once we are thoroughly familiar with some kind, we can discriminate individuals of the kind without explicit reference to a model. The Mohists themselves are concerned mainly with cases in 
which confusion or disagreement might arise in discriminating kinds and so explicit comparison with models may be necessary.

${ }^{20}$ Let me emphasize that the point is not that the agent is correct about how things seem or appear. It is that he is correct about some feature of how they actually are.

${ }^{21}$ References to the Xúnzľ give chapter and line numbers in Xúnzǐ (1966).

${ }^{22}$ I follow Lǐ (1979: 513) and Hansen (1992: 325) in reading "all those of the same kind and same affects" as the antecedent of the pronoun qi 其 (their) in the phrase qi tiān guān 其天官 (their sense organs) at 22/16, for I see no other plausible antecedent. The verb phrase yì wù 意物 at 22/16 I take to be roughly equivalent to yì wù 臆物 (to detect or measure things), yì 意 being used in a way similar to how it is at Xúnž̌ 26/14. A crucial interpretive point is that $y \grave{i}$ wù is unlikely to refer to mental representations or images of things, as, for instance, Knoblock (1994: 129) and Graham (2003: 213) interpret it. In contexts where it is used as a verb, as it is here, $y i$ 意 can be interpreted as “intend," "think," "detect," “assess," or "suspect," but is unlikely to mean "represent" or "form a mental image," as it refers to the directedness of the sense organs toward their object, rather than an "input" from the object through the senses to the heart. Moreover, were the text referring to images or representations, it would likely use the word xiàng 象, as it does a few lines later when it states that the heart "represents" (xiàng) the dào through verbal discrimination and explanation (22/40). Geaney correctly rejects the "mental representation" interpretation but takes yì wù to be a noun compound meaning roughly "intentional thing" (2002: 37-39). This reading is difficult to defend grammatically, since it makes the nominalizing particle $y \check{e}$ 也 redundant.

${ }^{23}$ Geaney suggests that since the text places a pragmatic condition on knowing, the form of knowledge it articulates is not perception (2002: 48-49, $203 \mathrm{fn} .85)$. Her reading is 
intriguing, but I think a simpler yet equally comprehensive interpretation is that the text is articulating a conception of perceptual knowledge or recognition that incorporates a pragmatic requirement. This interpretation coheres with Xúnžr's view that the activity of the sages is what divides things in the natural world into kinds (19/78-79) and thus underwrites our ability to have knowledge of those kinds. One must grasp the traditional, conventional distinctions embodied in language, as passed down from the sage-kings, in order to qualify as having perceptual knowledge.

${ }^{24}$ Here I agree wholly with Geaney in rejecting interpretations-such as Cua's (1985: 31), Watson's (1963: 142-43), and Knoblock's (1994: 130)—that ascribe a role to sense data or sense impressions in Xúnzǐ’s theory (2002: 201, n. 83). The text explicitly discusses only the "differentiating" activity of the sense organs and heart and the "verifying" activity of the heart (22/16-21). It mentions nothing corresponding to sense impressions or sense data. ${ }^{25}$ Dan Robins also notes these aspects of Xúnž̌’s explanation of error (2008, sect. 8). ${ }^{26}$ Geaney makes a series of similar observations (2002: 40-41).

${ }^{27}$ As we have seen, for both Xúnzǐ and the Mohists, cognition is based on discriminating different kinds of things. So Xúnzľ's account implies that some form of blinkering is inherent in the very structure of cognition and that any values we hold or dào we follow in some sense blinker us to alternative values and dào. This point is among the grounds for both the skeptical arguments and the normative stance of the Zhuāngzl̆. For further discussion, see Fraser (2006) and (2009b). Ironically, Xúnzǐ himself does not note these consequences of his view, but instead asserts that the dào of Confucius is comprehensive and unblinkered (21/27). ${ }^{28}$ See, for example, Zhuāngž 13/40, 17/6ff., 24/33ff., 25/74, and 33/11ff. (the last passage is probably a Hàn dynasty text). (Citations to the Zhuāngž̌ give chapter and line numbers in Zhuāngzǐ 1956.) A. C. Graham long ago noted that criticism of opponents' views as narrow 
or one-sided rather than outright wrong is common in third century B.C.E. and later texts (1989: 378). Much of the discussion in Book 2 of the Zhuāngž̌ is driven by the thought that in discriminating things one way rather than another, there is always that which we overlook and thus fail to see $(2 / 57-58)$.

${ }^{29}$ Compare Knoblock and Riegel (2000), sect. 13.3 and 16.7. Translations from the text are my own.

${ }^{30}$ Knoblock and Riegel (2000: 400). The Annals uses the graphs 宥 and 尤 for the word yò instead of 直 (see Zhuāngž̌ 24/34, 33/80), but all three graphs seem to express the same word.

${ }^{31}$ For discussions of the early Chinese metaphor of the heart as political sovereign and the sense organs as bureaucrats, see Sivin (1995) and Geaney (2002: 17-22).

${ }^{32}$ Donald Munro was the first to call attention to this aspect of the role of the heart in early Chinese thought and the intriguing contrast between it and Greek conceptions of the mind, which instead emphasize its role in knowledge and reasoning (1969: 51-59).

${ }^{33}$ Lì is "forethought," or thought directed toward determining what judgment or action to undertake.

${ }^{34}$ Some commentators suggest that the phrase $m o ̀ m$ 漠漠 refers not to a sound but to silence.

${ }^{35}$ Even in the case of the blind being unable to see the stars, Xúnzl's explanation is that their “functional proficiency” (用精) is “confused,” not that they are in some way cut off from the world.

${ }^{36}$ Xúnž̌’s discussion of perceptually confusing circumstances does not explicitly apply partwhole rhetoric to explain error. The emphasis is instead on competently noting when one's thinking is unclear or when some aspect of the circumstances produces "obscuration." But a 
part-whole explanation can easily be extended to fit the examples. If we attend only to part of the situation - the rough similarity in shape between a stone and a tiger, as viewed in the dark, or that in size between oxen and sheep, as viewed from a distance — then we might mistakenly take a stone to be a tiger or oxen to be sheep. But if we attend to all aspects of the situation, including the darkness and the distance, error is unlikely.

${ }^{37}$ This statement should be qualified in one respect. Some passages in the Zhuāngž question our ability to know the underlying causes or source of the things we observe-what is behind natural phenomena or the various attitudes we find within ourselves. For instance, the "Discourse on Evening Things Out" questions whether we can identify whatever it is that moves the "pipes of nature" and thus causes the activity of the myriad things $(2 / 9)$, whether we can know of a "ruler" or "master" within us that governs the other organs and from which our attitudes arise (2/15-18), and whether we can know what ultimately causes our behaviour (2/92-94). The gist of this line of skeptical questioning, however, is not that we know only appearance and not reality, but that our epistemic powers are fundamentally limited. In regard to certain questions, our ability to discriminate things cannot get off the ground, as there are no identifiable features to work with. On such issues, see too the exchange at Zhuāngž̌ $17 / 20-24$ and the dialogue at 25/59-82.

${ }^{38}$ On this point, see Fraser (2009b). Hansen has long argued that Zhuangist skepticism does not concern the reliability of sense perception (1983: 92 and 183, fn. 80).

${ }^{39}$ This paper is a revised and expanded version of material first presented in Fraser (1999). Earlier versions of the paper were presented in February 2009 at a seminar in the Department of Philosophy, University of Hong Kong, and in May 2009 at "New Directions in Chinese Philosophy," a conference celebrating the 60th anniversary of the Department of Philosophy of the Chinese University of Hong Kong. I thank participants in both events for many 
stimulating questions. For helpful criticisms and suggestions, I am grateful to an anonymous referee and especially to Jane Geaney, whose comments prompted numerous revisions. 